\title{
Why GPs should write case reports
}

As the editor of Cases Journal, I'm on a mission - trying to get all doctors, but especially GPs, to publish case reports regularly. Why?

Firstly, I believe every case report, particularly if written in the right way with reflection and research, has value, and I mean every case report, no matter how mundane it might seem. In Cases Journal (http://www.casesjournal.com) we will publish every case report that is ethical and understandable. They don't have to be 'original and important' because we believe that every interaction with a patient is unique and that every case offers an opportunity to learn.

Writing case reports allows, even obliges, doctors to explore and mine both the uniqueness and the learning. It will also help doctors remember that every case, no matter how routine to them, is important to the patient. And writing brings insight and requires precision of thought. Writing the case report may also help the doctors better understand the patients' narratives and perspectives, particularly if the doctors write the reports with their patients. Perhaps you, the doctor, might write the story and simultaneously ask the patient to do the same. My bet is that often you may be surprised by comparing the two; something new and unexpected may emerge.

These case reports should have value not only for the doctors who write them and their patients, but also for others as a means of learning. Medicine cannot be learnt without case histories. We learn most from our own cases, particularly perhaps those that have gone badly, but we can also learn from the cases of others - especially when the cases are similar to those we've managed and when the authors have worked hard to deepen their own understanding and to bring out the learning.

My second reason for urging everybody to write case reports is that there will be value in creating a huge database of reports, which is what we plan to do; building it not only from cases published in
Cases Journal and its sister publication, the Journal of Medical Case Reports, but also from cases that appear in other journals. This database will be open to all and use a sophisticated search engine. It will allow doctors and patients to find cases similar to theirs and discover what happened to them. This information will be most valuable with complicated cases where patients have multiple problems and chronic diseases, the cases that are the stuff of general practice and where evidence-based guidelines, which are usually based on evidence from patients without comorbidities, can provide only limited help.

My third reason is that I think that 'ordinary doctors', who have no incentive to write and publish and so usually don't, will gain something valuable for themselves from the act of writing. George Orwell in his essay Why I Write, describes four reasons for writing:

\section{'... sheer egoism ... to be talked about, to be remembered after death'; 'aesthetic enthusiasm ... perception of beauty in words and their right arrangement'; 'historical impulse'; and 'political purpose ... desire to push the world in a particular direction."}

I doubt that these reasons will chime with many GPs. More relevant may be the urging that comes from the Boston surgeon, Atul Gawande, in his marvellous book, Better. ${ }^{2}$ Gawande, who writes for the New Yorker and has won a MacArthur Grant (a 'genius grant,' as they are known), didn't write until he became a doctor:

'I [then] found I needed to write ... Because medicine is a retail enterprise, because doctors provide their services to one person after another it can be a grind. You can lose your larger sense of purpose. But writing lets you step back and think through a problem ... Most of all, by offering your reflections to an audience, even a small one, you make yourself part of a larger world."
Gawande says write anything, 'it need only add some small observation about your world.' But the easiest thing for doctors to write is a case report because that's what they experience, seeing patients every day. So I urge you to write case reports, partly for the benefit of the world but perhaps even more for your own benefit. Once you've got started you'll come to love it.

\section{Richard Smith}

\section{Competing interests}

RS is paid 2 days a month for editing Cases Journal, and it's more likely to flourish, and him with it, if lots of GPs write case reports.

\section{REFERENCES}

1. Orwell G. Why I write. Harmondsworth: Penguin, 2004.

2. Gawande A. Better: a surgeon's notes on performance. London: Profile books, 2007.

DOI: 10.3399/bjgp09X420806 